\title{
A bravura do gosto ${ }^{1}$
}

\section{Lúcia Schneider Hardt ${ }^{2}$ Rosana Silva de Moura ${ }^{3}$ Rodrigo Mafalda ${ }^{4}$}

\section{Resumo}

O gosto parece ser uma antítese da decadência. O gosto é uma luta constante consigo mesmo. Uma luta contra o nosso tempo, não se deixar levar pela fala rasa, única e para todos. Quais fios aprisionam o gosto para convertê-lo em unidade? Em que medida o gosto ganha credibilidade quando atinge a maioria. O tema do gosto nos alcançou por meio da obra de F. Nietzsche, O Caso Wagner - Nietzsche contra Wagner, em cujo texto o filósofo realiza uma crítica de si mesmo e também de Wagner enquanto sintoma de uma época. Nesse ponto introduzimos o debate sobre o gosto em outro cenário: o da educação. Gosto de dar à cultura e à formação um espaço para Dioniso.

Palavras-chave: O Caso Wagner, Gosto; Educação.

\section{Abstract}

The taste seems to be an antithesis to decadence. Taste is a constant struggle with yourself. A struggle against our time, not to be get carried away by a shallow, unique speech for all. Which strands imprison the taste to convert it into unit? To what extent does the taste earns credibility when it achieves the majority. The subject of taste has reached us through F. Nietzsche's The Case of Wagner - Nietzsche against Wagner, in whose text the philosopher criticizes himself and Wagner as a symptom of an epoch. At this point we introduce the debate about taste in another scenario: that of education. I like to give culture and formation a space for Dionysus.

Keywords: The Case of Wagner, Taste; Education.

\footnotetext{
${ }^{1} \mathrm{O}$ tema tratado neste ensaio foi, inicialmente, apresentado no II Seminário da Sociedade Brasileira de Filosofia da Educação (SOFIE), em setembro de 2016, em Campinas/SP. Tratando-se de uma pesquisa em curso e, por isso, desenvolvida também na interface com uma problematização com a escola, o texto, com este desdobramento sob o título Qual o gosto que o pedagogo tem pela escola?, integra uma proposta de livro organizado pela UFPR, obra prevista para o segundo semestre de 2017 (no prelo). Uma adaptação deste texto foi apresentada como palestra em outubro de 2016, no XXVIII Simpósio Catarinense de Administração da Educação, realizado na UDESC/Florianópolis

2 Professora Adjunta IV no Departamento de Estudos Especializados em Educação no Centro de Ciências da Educação da Universidade Federal de Santa Catarina (UFSC).

${ }^{3}$ Doutora em Educação (UFRGS), atuando em Filosofia da Educação no PPGE/UFSC.

${ }^{4}$ Mestre em Educação (UFSC), doutorando em Filosofia da Educação no PPGE/UFSC.
} 


\section{O gosto}

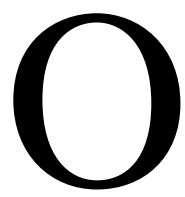

tema do gosto nos alcançou por meio da obra O Caso Wagner - Nietzsche contra Wagner, em cujo texto o filósofo realiza uma crítica de si mesmo e também de Wagner. Compulsivamente, quer se diferenciar da estética que se faz por efeitos, por pequenas explosões que buscam produzir um êxtase próprio da modernidade. Uma estética que deseja estender uma verdade a todos, criar emoções arrebatadoras para cavar espaços e prioritariamente produzir o homem da ação. Outra estética é possível, "aproxima-se sutil, leve, com polidez, move-se com pés delicados" (NIETZSCHE, 1999, p. 11). Essa outra possibilidade estética Nietzsche enxerga em Bizet. Outra música, outra sensibilidade. Outra pedagogia?

E Nietzsche insiste: “a adesão a Wagner custa caro". Nessa afirmação avalia sua própria decadência e seu primeiro gosto. Como livrar-se do gosto encharcado do seu próprio tempo, como ser atemporal, para além dele, para com bravura criar outro gosto.

Nesse ponto introduzimos o debate sobre o gosto em outro cenário: o da educação. Como leitores de Nietzsche e especialmente da obra já referida, somos tomados por uma inquietação: Qual o gosto e como ele se estabeleceu e vem determinando uma modalidade de formação, de educação? Esse gosto tem sinais de decadência? Precisamos formar segundo um gosto? Ou a questão seria mais de como estamos afastados da bravura para avaliar o gosto pelo qual somos consumidos.

O texto pretende fazer acontecer essa relação, essa analogia. Sem nenhuma pretensão de assemelhar-se ao filósofo, o que já seria um exagero, mas reconhecer na obra sua capacidade de nos fazer pensar o que é do nosso mundo. Suspeitamos que a questão do gosto para formar pessoas, tem andado meio decadente, desejando produzir efeitos, êxtases, convencimentos com pouca delicadeza e sutileza. ${ }^{5}$

\footnotetext{
${ }^{5}$ Em Ecce Homo, no capítulo intitulado "Porque escrevo bons livros", Nietzsche fala de sua qualidade de escritor, da leveza e do gosto, dizendo que compreendeu como se corrompia o gosto com o manuseio da sua própria obra: "[...] Não existem livros mais soberbos e ao mesmo tempo tão refinados quanto os meus; chegam esses, aqui e acolá, ao ponto mais alto a que se possa chegar: ao cinismo; é necessário, por isso, conquistá-los com dedos delicadíssimos, e ao mesmo tempo, com pulsos valorosos." (NIETZSCHE, 1985. p.3).
} 


\section{A corrupção do gosto}

Segundo a crítica de Nietzsche, a música de Wagner foi corrompida por uma vontade de redenção. Sempre alguém precisa ser corrigido, tocado. Insiste com a ideia da dedicação, fidelidade, pureza, verdade. Em alguma medida está em Wagner um princípio - “deves crer e precisas crer" (NIETZSCHE, 1999, p.15). A música foi convertida em religião, convertida em finalidade, a serviço do Estado. A produção dos efeitos vai evitando a ruminação sobre os absurdos. Quando a emoção é capturada a ruminação cessa. ${ }^{6}$

Outra corrupção do gosto: o excesso de otimismo. E, por mais paradoxal que possa parecer, o otimismo faz da arte de Wagner uma doença. Algo indigesto? Mesmo assim, parece solicitar uma análise. A corrupção do gosto cria atração pelo que se deveria evitar. Chamando atenção para aquilo do qual se 'deveria' abandonar, põe em cena, para o olhar e o ouvido, aquilo do qual já se teria instaurado a urgência em deixar. Nietzsche reconhece que caiu nessa armadilha, inerente a toda interpretação. Imaginou com Wagner reeditar a tragédia grega. Nada se realiza nessa direção, pois:

Wagner é uma grande corrupção para a música. Ele percebeu nela um meio para excitar nervos cansados - com isso tornou a música doente. Não é pouco seu talento na arte de aguilhoar os totalmente exaustos, de chamar à vida os semimortos. Ele é o mestre do passe hipnótico, mesmo os mais fortes ele derruba como touros. O sucesso de Wagner - seu sucesso junto aos nervos, e em consequência junto às mulheres - transformou o mundo dos músicos ambiciosos em seguidores da sua arte oculta. E não só os ambiciosos, também os sagazes... Hoje se faz dinheiro apenas com música doente; nossos grandes teatros vivem de Wagner. (NIETZSCHE, 1999, p. 19-20).

\footnotetext{
${ }^{6}$ Grande parte da obra de Nietzsche estabelece-se com a metáfora da ruminação e do estômago, enquanto uma "vontade fundamental do espírito" (NIETZSCHE, § 230, 1992, p.136) é o sentido de uma filosofia do Gosto. No caso específico de Nossas virtudes, na obra Além do bem e do mal, pode ser um conduzir: da multiplicidade à simplicidade, como vontade restritiva, conjuntiva, sequiosa de domínio e realmente dominadora. No sentido da força que se apropriaria do que lhe é estranho, assimilando o novo ao antigo e enquadrando novas coisas em velhas divisões. Certo crescimento a serviço dessa mesma vontade. Ou, uma brusca decisão de não saber, conforme suas palavras, "[...] de encerrar-se voluntariamente, um fechamento de janelas, um dizer Não interiormente a essa ou aquela coisa, um não deixar que algo se aproxime, um estado defensivo ante muita coisa conhecível, uma satisfação com o obscuro, com o horizonte que se fecha." (NIETZSCHE, § 230, 1992, p.137). Tudo isso necessário e conforme o grau da força apropriadora do espírito, pensada a partir do autor: "de sua força digestiva, usando uma imagem - e realmente o "espírito" se assemelha mais do que tudo a um estômago." (NIETZSCHE, § 230, 1992, p.137). Enfim, ele acrescentaria: de um gosto da incerteza e ambiguidade, como vontade de aparência, e aquele sublime pendor do homem de conhecimento, profundo, plural e radical.
} 
De certa forma, esteticamente ruminamos o(s) gosto(s). Para Nietzsche, Wagner tornou-se indigesto. Dizendo em outras palavras, o instinto ficou debilitado, é mais fácil ser gigantesco que belo e no gigantesco revela-se a corrupção. $O$ belo é sutil, não suporta testemunhas e não se vincula a muitos. Nessa arte doente, o caos é expulso e só ele pode fazer intuir o todo. Wagner converte o todo em um artefato, a vontade fica desorganizada, converte-se em cálculo para produzir efeitos e conseguir seguidores. A vida fica restrita e em toda parte encontra-se certa paralisia produzida pelas pequenas unidades de êxtase geradas por Wagner em sua música. Seu estilo dramático o torna admirável como “inventor do mínimo, na criação do detalhe” (NIETZSCHE, 1999, p. 24). Wagner é um inventor para as massas, sabe seduzi-las e capturá-las oferecendo consolo e compaixão.

$\mathrm{Na}$ crítica de Nietzsche fica destacado um Wagner encenador, um homem do teatro, capaz de demorar-se em um gesto e, como um tirano, convocar o público para a ação, seja ela política ou religiosa. Conseguiu fazer crescer a capacidade de expressão da música pelo estilo dramático para produzir efeitos e instrumentalizá-los na captura do público. As cenas produzem um drama convertido em Wagner por uma "ação" que exige efeitos. Segundo Nietzsche, converter o drama em ação é a maior desgraça, pois retira do drama a cena que retrata um lugar, o suceder da vida, para insistir com uma finalidade. Tudo se congela para a finalidade. Em sua origem o drama é um suceder da vida e não um apelo ao fazer.

Scarlet (2014) prefere não falar em oposição considerando a relação Wagner/Nietzsche, pois o termo reduziria a importância do conceito "superação" tão forte na obra do filósofo. Melhor escolher a palavra antagonismo. Encarando Wagner

como um antagonista ou antípoda, Nietzsche o interpela e, ao fazê-lo, é com si mesmo que procede a um ajuste de contas. Nesse duelo e diálogo que estabelece com o compositor, ele se toma em mãos e avalia o próprio processo: "talvez ninguém cresceu mais perigosamente com o wagnerismo, ninguém resistiu mais duramente contra ele, ninguém se alegrou mais por dele livrar-se”. É também nesse sentido que podemos entender tratar-se aqui de um processo de cura. (SCARLET, 2014, p. 203).

A cura contra a decadência exigiu a presença do filósofo, no caso exigiu a presença de Nietzsche como pensador para criar uma disciplina própria para "tomar partido contra tudo doente em mim, incluindo Wagner, incluindo Schopenhauer, incluindo os modernos sentimentos de "humanidade" (NIETZSCHE, 1999, p. 9-10). Uma guerra não contra 
pessoas, mas contra o arcabouço cultural inventado pelo filisteu da cultura. A cura de Nietzsche dependeu inclusive de sua luta contra si mesmo, de perceber a corrupção desse gosto apresentado como refinado e consolador. Seus alvos de ataque foram vivenciados por ele mesmo; contudo, percebe a doença e descobre outra vez a grande saúde.

Segundo Scarlet,

É digno de nota o parentesco que o "caso Wagner" apresenta com o "problema de Sócrates". Ao intitular um dos capítulos do Crepúsculo dos ídolos, Nietzsche não tem em vista investigar o caráter problemático do ateniense, mas quer tomá-lo enquanto aquele que encarna um problema. Casos aparentados, tanto Sócrates quanto Wagner constituem objeto de sua atenção. Entendendo que o filósofo deve ser "médico da civilização", é nessa condição que se disporá a examinar a enfermidade que neles se manifesta. (SCARLET, 2014, p. 206).

De certa forma, e nos dois casos, o filósofo vai examinar os sintomas de uma cultura, isto é, a "azia" cultural instalada por Sócrates e por Wagner. Para Nietzsche, uma cultura indigesta. Outro caso em Nietzsche poderia ser identificado quando avalia os estabelecimentos de ensino e em todos esses casos o que está em foco é a percepção da decadência e a produção de seus efeitos, conforme já sinalizamos, de um propósito de captura dos efeitos para atendimento dos propósitos do Estado. Nas instituições de ensino o descuido é com a Bildung e, nesse entorno, a filosofia ou, certa perspectiva filosófica, encontra o horror da decadência. Nesse caso, o horror convoca a pedagogia, sugerindo repensar a arte de formar pessoas. O tema é muito bem abordado por Bárbara Stiegler (2009), em um artigo específico que apresenta a crítica de Nietzsche a uma ideia moderna de Bildung. O assunto interessa ao jovem Nietzsche, pois atua como docente e enfrenta todo tipo de adversidade em sua instituição.

O terror diante da literatura pedagógica e em geral tomada por mãos grosseiras (NIETZSCHE, 2003, p. 66) deve nos convocar a pensar mais uma vez sobre a grande arte, a técnica da formação cultural. A melhor pedagogia não vem do espanto, da admiração, mas vem do terror daquilo que está em curso nos estabelecimentos de ensino. Por onde começar outra pedagogia? ${ }^{7}$

\footnotetext{
${ }^{7}$ No anexo dos Escritos sobre Educação (2009) temos fragmentos póstumos e aforismos que apresentam as críticas em geral de Nietzsche sobre uma ideia de formação, importantes desdobramentos sobre o "Erudito" e o problema do "ganha-pão", sobre estes que servem à verdade quando ela está em condições
} 


\section{A corrupção da pedagogia, um tipo de horror}

A decadência conduz a uma precariedade de forma, de gosto, leva a barbárie. A barbárie acontece quando abandonamos os vivos no caos, desistimos de formar para a força e organização do caos. O caos que não é barbárie, mas o convite para a invenção. A vida solicita forma, medida, organização. Nietzsche fica tomado pelo terror que contempla nas instituições que abandonam sua função de estruturar, delimitar e organizar o caos.

Voltamos à bravura do gosto, uma força capaz de livrar-nos do que nos consome e captura - o caso Wagner para Nietzsche e para nós educadores - o gosto por uma pedagogia que deseja a admiração da multidão. A multidão que elimina o indivíduo, faz desaparecer o que se diferencia. O que aprender com Nietzsche para curar-se desse traço da decadência?

Nietzsche (1999, p.18), ao fazer uma paródia de uma expressão de Goethe, que clama por luz, mais luz, anuncia em seu próprio tom: ar, mais ar. Licht e Luft são necessários, pois como diz nosso filósofo, os filisteus da cultura (os Eruditos) instalam tudo que lhes é anterior na sombra. Nietzsche clama então outra vez por ar e luz para enfrentar a corrupção do gosto. Outro clamor, segundo nosso ponto de vista, ainda precisa ser convocado: silêncio, mais silêncio, para enfrentar o excesso da palavra, do normativo, das políticas que supostamente democratizam, integram e salvam a educação, deslocando quase nada em termos estruturais.

A adesão a Wagner custou caro, diz Nietzsche. Repete isso várias vezes para admitir que a adesão nunca é inofensiva, acaba por corromper o gosto. O gosto com Wagner tem a medida da sede por abundância, e por isso investe-se de uma melancolia da incapacidade.

A adesão à pedagogia da multidão custa caro. Ela quer ser absoluta, total e alcança a todos por meio da mediocridade. O gosto do singular não é oposto da multidão, talvez seja um antídoto para a corrupção na pedagogia. Stiegler (2009) nos ajuda nesse contexto

de ajudá-los. Desta condição, Nietzsche analisa as questões e os horrores em torno da educação da sua época. Neste caso, a imagem do estômago aparece agora, como o "despenseiro do espírito" (Ingenii largitorventer). Com essa imagem, permite-se traçar uma fronteira entre verdade produtiva e verdade improdutiva, conforme Nietzsche: "esta última não ajuda a ganhar o pão e, na medida em que ela custa esforços e tempo que poderiam ser dedicados à primeira, ele impede mesmo fazê-la." (SOBRINHO, 2009, p.283) Neste sentido a ruminação propriamente espiritual cederia lugar ao ganha-pão, ao estômago, no caso, o despenseiro do espírito. O horror e característica da corrupção moderna dos estabelecimentos de ensino em torno de promoções e gratificações. Estas, seguindo com a imagem seriam "Os borborigmos de um estômago que padece" (SOBRINHO, 2009, p. 283). 
quando anuncia em seu artigo que sempre que a massa é apenas reunida emocionalmente corre-se o risco de destruir a singularidade e de redobrar o perigo de uma multidão sem forma, que alcança apenas uma organização nas suas formas mais rudimentares, incapaz de criar. Nietzsche vai defender ainda jovem uma aristocracia do espírito, uma possibilidade para poucos. Aqueles que, por conhecerem a abundância, sabem selecionar, são aqueles que operam não por oposição, mas por diferenciação. Apresentar essa aristocracia não significa vinculá-la a qualquer outro critério, muito menos econômico. Cabe reconhecer o espírito que se faz livre para operar por diferenciação que destina sua força e potência para resistir a qualquer "deixar fazer", e pelo contrário deseja convocar o ser humano vivo a fazer algo para enfrenta o horror. $O$ fazer não é seguir o comum, mas lutar contra o comum já que a bela forma é oriunda da mais sofisticada disciplina capaz de enfrentar o ganha-pão, a dispersão, o caos e o medíocre.

Como nossa pedagogia vem enfrentando o medíocre? Em que medida estamos afastados por demais da mais bela e sofisticada disciplina? Afastados da obediência às formas primeiras: da língua, da leitura e da escrita? Admiramos a pedagogia quando tudo permite, quando conduz a um "deixar fazer", ficamos extasiados com a multidão em constante mobilização. Qual forma está aí? Que tipo de organização do caos se tornou possível? Apenas inserir-se em uma parcela da multidão? Podemos nos admirar disso ou ainda estamos diante do horror que clama por outra pedagogia?

Nietzsche, em sua crítica aos estabelecimentos de ensino, denuncia uma pobreza do espírito pedagógico, pois estão faltando indivíduos com talentos inventivos. E, como sabemos, no limite da mediocridade que precisamos superar hoje, sob esta luz da crítica nietzschiana (SOBRINHO, 2003, p. 27), o próprio termo "talento" se encontra contaminado pela perspectiva empresarial. Homens de talento, hoje, aqueles que são formados para o êxito de projetos das empresas amarradas nos egoísmos de Estado e/ou mercado. Nesse sentido, o inventivo converte-se em práxis para enfrentar a pobreza, a falta de abundância tão necessária para a formação humana.

Qual poderia ser nosso pronunciamento para enfrentar a pobreza pedagógica em nossa formação? Longe de deixar acontecer, precisamos também resgatar qual obediência e disciplina promovem a liberdade. Obediência à forma, as leis da própria língua materna visando a introduzir a necessidade de uma sofisticada relação entre o caos e sua organização. Ser obediente às regras da língua, afirma Stiegler (2009), é uma outra forma de contemplar um modelo que é por definição coletivo e exige dos indivíduos dedicação 
e disciplina para ser livre. A pobreza pedagógica instala-se sempre que imaginamos estar desde sempre livres, dispensando qualquer obediência para reconhecer um modelo, qualquer espelho. Dar as costas a esse processo produz indivíduos desprovidos de estilo e voz própria. Surge a fabricação da massa em geral para ser manipulada e governada.

Segundo Stiegler (2009), sempre que nos decretamos livres desde o início nos processos de formação, a tendência é fazer proliferar indivíduos mais adaptáveis, dóceis e menos livres. Servos do imediato, do instante. Obediência e hábito podem iniciar outra pedagogia. Afinal, o que é preciso enfrentar?

Nietzsche presiente que todos los grandes fenómenos políticos y sociales del siglo XIX conspiran en la misma dirección. Trátese del Estado moderno, del mercado, del socialismo o de la democracia, todos persiguen de forma rigurosa el mismo objetivo: la producción de una masa uniforme y homogénea, compuesta de individuos sin individualidad, fácilmente adaptables al programa de dominio y de cálculo, intensificados por la revolución industrial. Pues en adelante no se trata sólo de "hacer[se] señor y poseedor de la naturaleza" (Descartes). El programa de dominio se ha convertido en aquel de un cálculo integral de todo lo real que busca, lógicamente, anexarse al campo de la vida humana y de su individuación. Desde ahora, es a la persona humana a la que se trata de hacer previsible y calculable, y es la individuación, fuente de imprevisibilidad, lo que se trata de destruir desde entonces. Tal es el envite sociopolítico de la nueva Bildung, destructora de la "verdadera Bildung": fabricar una masa previsible y calculable, que se adapta sin resistencia a las exigencias de un cálculo integral de la naturaleza (no sólo inorgánico, sino también viviente y humano). (STIEGLER, 2009, p. 163).

Longe de querer dominar a natureza, outra pedagogia quer provar o tanto de força e potência que o humano tem para criar, produzindo experiências, servindo-se das ferramentas mais adequadas para isso e que podem ser acessadas por meio dos estabelecimentos e ensino, sendo

incubadoras o esos semilleros en los cuales se cultivan las excepciones, capaces de arriesgarse al terror y exponerse al exceso del caos, a la vez que lo organizan. Lo inaceptable es que estén en vías de volverse lo contrario, unas instituciones donde se impide, a la vez, la individuación y la exposición al exceso, con miras a fabricar una masa homogénea, adaptable e incondicionalmente obediente al programa de un 
cálculo íntegro de lo dado: "Los más nobles de vuestros jóvenes respiran allí penosamente, como abrumados, y los mejores, perecen" (NIETZSCHE, 1988f, tomo 1: 747). (STIEGLER, 2009, p. 165).

O caso Wagner implica um desejo de livrar-se de uma falsificação da cultura que produz um homem decadente, "que diz Sim e Não com o mesmo fôlego" e Nietzsche contra Wagner quer de novo dançar, zombar do perigo, impedir que a vida seja negada. Nietzsche com bravura inaugura outro gosto, outra arte, colocando-se no mundo para indagar, pensar e fazer. Curar-se da doença.

E nós, pedagogos, o que queremos? Perceber onde pode estar o desvio da formação e insistir em uma travessia que não se contenta em ser dirigido, orientado, manipulado, mas deseja aprender a organizar o caos que todos os dias a vida nos apresenta. Não existe uma ideia plena de formação, capaz de oferecer um modelo seguro para enfrentar o caos. O caos é sempre destruidor, potente e exigirá uma presença qualificada. Não basta estar vivo, conformar-se com que já está organizado, será necessário sempre formar-se a si mesmo para em cada situação selecionar qual encaminhamento é o mais adequado. Ser capturado pelas oposições designa uma grande possibilidade de empobrecimento. Operar por diferenciação significa ainda mais uma vez ousar pensar por conta própria sem afastar-se dos outros tantos que também pensam, decidem e selecionam.

Mas o que somos livres mesmo para fazer? Qual é possibilidade de afirmar nosso gosto? Onde estará a bravura?

A reflexão de Constâncio (2014) sobre o aforismo 560 de Aurora é especialmente interessante. Do aforismo ele discute o que é liberdade, caráter e consciência em Nietzsche. A metáfora do jardineiro é tomada para discutir a possibilidade de "criação de si”. Não somos totalmente determinados, nem totalmente livres. Se o corpo é a grande razão, em nós muitas coisas pensam: pulsões, instintos, forças. Nem por isso a consciência desaparece, mas trata-se apenas de superfície, pois o terreno subterrâneo ainda não mostrou toda a sua potência. Muitas forças disputam espaço em nosso corpo, será preciso ordenar, coordenar, hierarquizar aquilo que vive no corpo. O que vive avalia e o que é avaliado implica um tanto de coisa que nem sempre reconhecemos. Uma pulsão é dinâmica e disputa uma posição entre outras tantas forças, designando a multiplicidade do corpo vivo. 
Assim, diz Constâncio (2014, p. 169): "No aforismo 560 da Aurora, Nietzsche quer dizer que, até um certo ponto e num certo sentido, somos livres para coordenar e organizar de diferentes maneiras a multiplicidade das pulsões e afectos que compõem o corpo." Coordenamos em função de uma necessidade que, parceira da liberdade, faz entender a função do jardineiro referido no aforismo acima quando deseja coordenar, organizar, hierarquizar o múltiplo. Liberdade que, como diz Constâncio, tem a dimensão de uma contingência. Fazer o jardim não é algo apenas calculável seguindo determinadas leis. Aos nossos olhos, um jardim nasce da uma natureza sem lei, sem cálculos previsíveis, e o que é vivo se faz a cada instante exigindo uma espécie de presença para criar. $^{8}$

Nesses termos:

Este facto que permite a Nietzsche rejeitar o conceito de "livre-arbítrio" e, ao mesmo tempo, preservar a ideia de liberdade - ou, mais exatamente, conceber um novo conceito de liberdade. Para Nietzsche, um organismo é "livre" quando define ele próprio o "estilo" do seu carácter, quando dá a si próprio a "lei" que o rege - i.e. quando as avaliações e os valores que o dominam são tecidos ou criados pelo próprio organismo. (CONSTÂNCIO, 2014, p. 172).

Aquilo que vive quer respirar. Isso vem de uma necessidade, de escolhas orgânicas e também profundamente pessoais. A liberdade como criação implica uma intensificação de cada corpo que pensa "produzindo uma individualidade do instinto" (CONSTÂNCIO, 2014, p. 173). Implica livrar-se do que é gregário, das avaliações que não são próprias e insistem em grudar-se em um corpo que pensa e estranha o que o domestica. Nem todos os corpos suportam essa luta. Na perspectiva da filosofia de Nietzsche, a hierarquização dos instintos acaba por reconhecer a multiplicidade de forças no corpo, que não é o caos, mas exige uma ordenação em um plano artístico que pode ser como nesse texto queremos defender uma espécie de gosto por outra pedagogia. Para esta outra pedagogia, deixar-se orientar apenas pela consciência é muito limitador, impede o desenvolvimento do instinto. Contudo, não podemos dispensá-la. Ela apenas é muito simplificadora considerando a complexidade da grande razão do corpo. "A perspectiva em que o corpo

\footnotetext{
${ }^{8}$ Segundo Nietzsche (1999, p. 73), deveríamos respeitar mais o pudor com que a natureza se escondeu por trás de enigmas e de coloridas incertezas.
} 
se revela como multiplicidade de pulsões e afectos é, a perspectiva do corpo vivido." (CONSTÂNCIO, 2014, p. 180). Assim, existe um sujeito em Nietzsche, não em termos cartesianos e nem kantianos, mas "um sujeito-multiplicidade" que está em constante deslocamento, devir, e não estabelece qualquer ponto fixo e duradouro, ainda que sempre coordenando, organizando e hierarquizando forças, impulsos, instintos. Espiritualizar um corpo que pensa, revela um gosto, que nasce da interface entre um sujeito-multiplicidade, liberdade e estilo que cada vez de novo indaga: O que somos livres para fazer?

Em tempos de extremos direcionamentos, no campo da política, da pedagogia, dos costumes, lembrar-se dessa indagação parece ser suficiente para iniciar um debate sobre a bravura e o gosto.

Assim,

o "jardineiro" que "cultiva" as sementes de uns afectos e não de outros, que faz isso "com bom ou mau gosto", que o faz "ao estilo francês, inglês, holandês ou chinês", que deixa "a natureza agir por si e providenciar apenas, aqui e ali, um pouco de ornamentação e limpeza", ou, que, em vez disso, deixa "as plantas crescerem com as suas vantagens e empecilhos naturais e lutarem entre si até o fim" (A 560) também "ele" e os "seus" pensamentos são apenas "causas catalíticas" da transformação do carácter, ou "instrumentos" do próprio carácter. (CONSTÂNCIO, 2014, p. 188. Destaques do autor).

Em tempos de prevalência de um gosto apenas binário, orientado na expressão de ou este oи aquele, pensar sobre a bravura possível de outro gosto, capaz de lutar contra as adesões já existentes, tal como Nietzsche fez em relação a Wagner, exige de um corpo vivo disposição a dar a si um estilo próprio, um gosto único, ainda que sempre em deslocamento. Sempre em tensão com aquilo que pode.

Assim, outra pedagogia implica, eventualmente, desgarrar-se do que conhecemos, estranhar aquilo que valorizamos, resistir ao convite das multidões, afastar as mãos grosseiras porque viver como diz Nietzsche (1992, p. 17) não é desejar ir para trás, mas desejar ir embora, um pouco mais de força, impulso, ânimo, senso artístico e desejaríamos ir para além - não para trás!

Nietzsche, ao desejar curar-se de Wagner, "sente o desejo de abrir um pouco mais a janela. Ar, mais ar!!” (NIETZSCHE,1999, p.18). Nesta direção qual é o ar que estamos 
precisando? Quais são as mãos grosseiras que andam cuidando da Pedagogia? Será que aquilo que deveria ser evitado nos atrai?

Um pouco mais de ar e luz, são ainda necessários.

\section{Referências}

CONSTÂNCIO, J. O que somos livres para fazer. Reflexão sobre o problema da subjetividade em Nietzsche. In: MARTON, S.; MAYER BRANCO, M. J.; CONSTÂNCIO, J. (org.). Sujeito, décadence e arte: Nietzsche e a modernidade. Lisboa; Rio de Janeiro: Tinta da China, 2014.

NIETZSCHE, F. Além do bem e do mal. Prelúdio de uma filosofia do futuro. São Paulo: Companhia das Letras, 1992. . Aurora. Trad. Mário D. Ferreira Santos. Petrópolis, RJ: Vozes, 2008. . Ecce Homo. Trad. Lourival d Queiroz Henkel. Ed. Ediouro - RJ. 1985. . O caso W agner. Trad. Paulo César de Souza. São Paulo: Companhia das Letras, 2009. SCARLET, M. Modernidade e décadence: Wagner e a cultura filisteia. In: MARTON, S.; MAYER BRANCO, M. J.; CONSTÂNCIO, J. (orgs.). Sujeito, décadence e arte: Nietzsche e a modernidade. Lisboa; Rio de Janeiro: Tinta da China, 2014.

SOBRINHO, N. Apresentação. A pedagogia de Nietəssche. In: Escritos sobre educação. Friedrich Nietzsche. Trad., apresentação e notas de Noéli Correia de Melo Sobrinho. Rio de Janeiro: Ed. PUC-Rio; São Paulo: Ed. Loyola, 2009.

STIEGLER, B. Nietssche y la crítica de la Bildung. 1870-1872: los envites metafísicos de la pregunta por la formación del hombre. Revista Educación y Pedagogía, v. 21, n. 55, septiembrediciembre 2009. 